\title{
An approach to identify urban groundwater recharge
}

\author{
E. Vázquez-Suñé ${ }^{1}$, J. Carrera ${ }^{1}$, I. Tubau ${ }^{1,2}$, X. Sánchez-Vila ${ }^{2}$, and A. Soler ${ }^{3}$ \\ ${ }^{1}$ Institute for Environmental Assessment and Water Studies, Spanish National Research Council, IDAEA-CSIC, \\ Barcelona, Spain \\ ${ }^{2}$ Department of Geotechnical Engineering and Geosciences, Technical University of Catalonia, UPC Barcelona Tech, \\ Barcelona, Spain \\ ${ }^{3}$ Grup de Mineralogia Aplicada i Medi Ambient, Dep. Cristallografia, Mineralogía i Dipòsits Minerals, Facultat de Geologia, \\ Universitat de Barcelona, Barcelona, Spain
}

Received: 25 February 2010 - Published in Hydrol. Earth Syst. Sci. Discuss.: 22 April 2010

Revised: 4 October 2010 - Accepted: 8 October 2010 - Published: 27 October 2010

\begin{abstract}
Evaluating the proportion in which waters from different origins are mixed in a given water sample is relevant for many hydrogeological problems, such as quantifying total recharge, assessing groundwater pollution risks, or managing water resources. Our work is motivated by urban hydrogeology, where waters with different chemical signature can be identified (losses from water supply and sewage networks, infiltration from surface runoff and other water bodies, lateral aquifers inflows, ...). The relative contribution of different sources to total recharge can be quantified by means of solute mass balances, but application is hindered by the large number of potential origins. Hence, the need to incorporate data from a large number of conservative species, the uncertainty in sources concentrations and measurement errors. We present a methodology to compute mixing ratios and end-members composition, which consists of (i) Identification of potential recharge sources, (ii) Selection of tracers, (iii) Characterization of the hydrochemical composition of potential recharge sources and mixed water samples, and (iv) Computation of mixing ratios and reevaluation of endmembers. The analysis performed in a data set from samples of the Barcelona city aquifers suggests that the main contributors to total recharge are the water supply network losses $(22 \%)$, the sewage network losses $(30 \%)$, rainfall, concentrated in the non-urbanized areas (17\%), from runoff infiltration (20\%), and the Besòs River (11\%). Regarding species, halogens (chloride, fluoride and bromide), sulfate, total nitrogen, and stable isotopes $\left({ }^{18} \mathrm{O},{ }^{2} \mathrm{H}\right.$, and $\left.{ }^{34} \mathrm{~S}\right)$ behaved quite conservatively. Boron, residual alkalinity, EDTA and Zn did not. Yet, including these species in the computations did not affect significantly the proportion estimations.
\end{abstract}

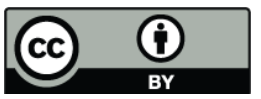

Correspondence to: E. Vázquez-Suñé (enric.vazquez@idaea.csic.es)

\section{Introduction}

Groundwater is increasingly recognized as a factor in urban management (see reviews by: Lerner, 1996; Chilton et al., 1997; Eyles, 1997; Chilton, 1999; Ellis, 1999; Llamas and Custodio, 2002; Howard and Israfilov, 2002; AIH_GE, 2004; Vázquez-Suñe et al., 2005a). On one hand, some cities still show overexploitation with a series of unwanted outcomes such as subsidence, or deterioration in water quality due to a number of causes including seawater pollution. On the other hand, groundwater pumping has been abandoned in many cities because of pollution and/or changes in land uses (notoriously relocation of industries). This has caused heads to rise, leading to flooding and potential structural damage to underground urban structures. Controlling heads rise may demand groundwater pumping in selected locations. Pumping may also be needed to address the increasing demand of water in a sustainable way. Amongst other things, this requires understanding the processes affecting water chemical and microbiological quality. A proper assessment of groundwater quality involves the quantification of overall recharge, as well as the quality assessment of the various sources involved.

Evaluating recharge in urban environments is essentially different from that in natural systems for two reasons: (1) recharge sources are radically different and (2) less experience is available. Surface infiltration is greatly reduced because a large portion of surface area is virtually impervious. Therefore, most rainfall becomes runoff, which is diverted to a drainage system. However, reductions in direct infiltration can be counterbalanced by reductions in evapotranspiration. Moreover, new sources of recharge may arise in cities, such as losses in the sewage system (Wolf et al., 2004; Blackwood et al., 2005) or in the water distribution system (world-wide losses exceed $50 \mathrm{~L} /$ person/day, but reported

Published by Copernicus Publications on behalf of the European Geosciences Union. 
figures in particular locations have been estimated to go up to $180 \mathrm{~L} /$ person/day; Kim et al., 2001).

Evaluating the recharge coming from the different sources is necessary for several reasons. First, overall recharge may be best evaluated if the relative importance of each source is known, because some of the sources may be easier to estimate than others. Second, pollution risk and geochemical processes depend on the chemical and biological signatures of recharge waters. Finally, management decisions, such as the reduction of losses and the increase in performance of distribution systems (Thornton et al., 2008), can be best supported if the relative importance of each recharge source is known.

The joint evaluation of recharge rates and quality should probably be best achieved through flow and solute transport modelling when long head and concentration records are available. Inverse modeling may prove a good tool for total recharge evaluation (Vázquez-Suñé et al., 1999; Yang et al., 1999; Bauer et al., 2001; Hussein and Schwartz, 2003; Dahan et al., 2004; Trowsdale and Lerner, 2003, 2007; Cox et al., 2007). However, this type of modeling does not help in identifying the contribution of each particular source to the total recharge.

Quantifying recharge sources is not an easy task. Direct measurement is possible only in a few cases. Specific tests need to be performed to evaluate sewer losses (Wolf et al., 2004; Blackwood et al., 2005), but their reliability is uncertain (Lerner, 1990). In fact, we have not found direct estimates of sewer losses in the scientific literature. There are several "water associations" (IWA, AWWA, see their web sites) that deal with Water Loss Control and work to provide operations accountability by reliable supplies auditing and by implementing controls to keep system losses to low levels. Leakage management methods are based on hydraulic control of the sewer network, detection of leakage hotspots and/or water budgets (Puust et al., 2010). None of these is based on groundwater hydrochemistry and quality assessment. Rainfall recharge in urban areas can only be measured in expensive pilot studies whose representativity is limited. In fact, it is likely that most rainfall recharge in highly urbanized areas does not occur by direct infiltration but by losses during runoff collection paths. The same caution note is applicable to the interaction between groundwater and urban surface water bodies like rivers or lakes (Hussein and Schwartz, 2003; Wakida et al., 2005; Cox et al., 2007). Water supply losses are easier to measure either by overall balance or by minimum night flow. Yet, they are uncertain. Even if total losses are known, their spatial distribution is usually not (Valdés and Castelló, 2003). Given these uncertainties, mixing ratios can be used to better estimate the relative importance of different sources of recharge.

Computation of mixing ratios is illustrated in Fig. 1 when two sources of recharge exist. Assuming two conservative species, the concentrations $C_{1}, C_{2}$ of a mixture are linear combinations of those of the end-members with weights

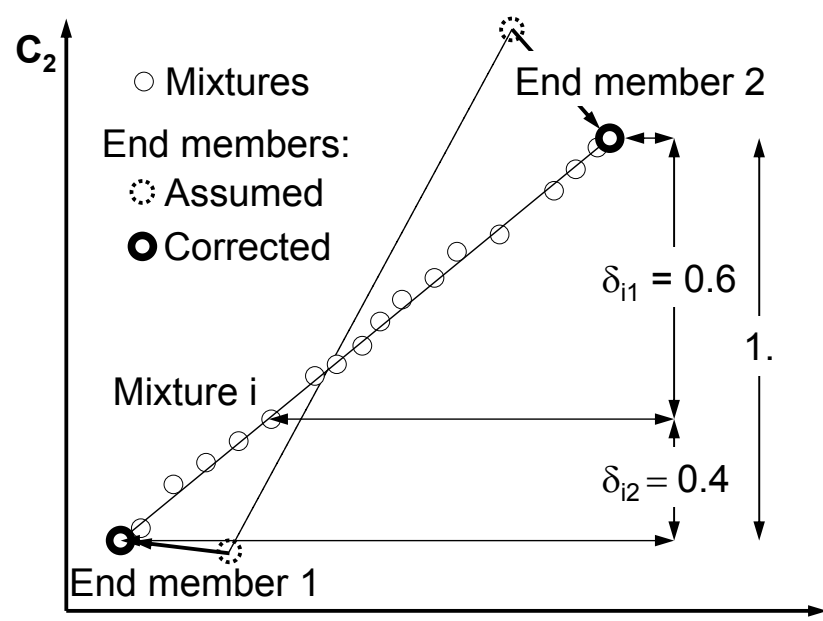

$\mathrm{C}_{1}$

Fig. 1. Schematic representation of mixing calculations with uncertain end-members. Source 1 contains $1000 \mathrm{mg} / \mathrm{L}$ of Chloride $(\mathrm{Cl})$. Source 2 contains $0 \mathrm{mg} / \mathrm{L}$ of $\mathrm{Cl}$. A measurement of $400 \mathrm{mg} / \mathrm{L} \mathrm{im}-$ plies that $40 \%$ of the water in the sample is coming from source 1 , while $60 \%$ is coming from source 2 . Mixtures concentration data are often affected only by measurement errors, much smaller than uncertainties of end-member concentrations. The latter can be corrected to be consistent with mixtures prior to conventional mixing calculations.

given by the mixing ratios. Variations of this concept have been widely used both in surface and groundwater hydrology. They include (1) End-Member Mixing Analysis (EMMA) (Hooper et al., 1990; Hooper, 2003; Christophersen et al., 1990; Christophersen and Hooper, 1992; James, et al., 2006; Jones et al., 2006); (2) box models (Neal et al., 2004); (3) Mixing ratios (Schemel et al., 2006; McLaughlin et al., 2007; Bickle et al., 2007). The concept has been generalized to multivariate mixing cell models (Adar and Neuman, 1988; Adar et al., 1988; Adar and Nativ, 2003; Dahan et al., 2004). Estimation of mixing ratios allows the computation of reaction rates for nonconservative solutes. This can be done from mass balance considerations (Parkhurst and Appelo, 1999) or by direct evaluation invoking the space-time distribution of mixing ratios for instantaneous reactions (De Simoni et al., 2007) or for non-instantaneous (Sanchez-Vila et al., 2007).

Traditional mixing ratios computations require that the concentrations of end-members are different and accurately known. Actually, they may be neither. First, concentrations of the end-members sources rarely differ as much as in the example of Fig. 1. In fact, a first challenge is to identify conservative species that are markedly different in each recharge source. Second, the required number of species to be used in a mass balance methodology grows with the number of potential sources (one needs, at least, $n e-1$ species, where $n e$ is the number of end-members). Therefore, species 
selection becomes especially difficult in cases with many potential end-members. Finally, the concentrations of the different species at the end-members may not be known with certainty. They can be highly variable in space and, especially, time (consider, for example, the case of a sewer carrying both waste and runoff water, which is quite common in the Mediterranean areas). Moreover, recharge may not be constant in time, so that the average concentration may not be representative of the recharge water. For example, most river recharge may occur during floods (Vázquez-Suñé et al., 2007), when most chemical species display below average concentrations. This problem is also illustrated in Fig. 1. Whenever several mixtures can be identified, the concentration data in the mixtures can be used to improve the estimation of end-members concentrations.

To address these specified difficulties, Carrera et al. (2004) developed a methodology to perform mixing ratios calculations while acknowledging the uncertainty of end-members concentrations. However, application to real cases with numerous end-members, such as urban recharge, has been hindered by several problems. The first one relates to limited experience on the selection of appropriate tracers. The second one is colinearity, which causes the solution to be nonidentifiable or unstable. That is, small changes in input data (for example, standard deviations of concentration measurements) result in large changes in the solution. This kind of problems can be fixed by constraining the mixing ratios for some end-members, which is often possible.

The objective of this paper is to define a methodology to overcome the above problems, so as to evaluate the relative contribution of different end-members to a set of mixed samples. The methodology is applied to the assessment of recharge sources in the Barcelona city aquifers.

\section{Methodology}

The proposed approach consists of four steps:

1. Identify the potential sources of recharge,

2. Hydrogeochemical characterization of recharge sources and mixed water samples. Select chemical species (tracers) to be used in the analysis,

3. Compute mixing ratios.

4. Iterate the process including reevaluation of the endmember and tracer selection based on the results of step (3).

\subsection{Identify the sources of recharge}

Identifying recharge sources is a site specific issue, so that few general recommendations can be given. Basically, it requires understanding the system. Water balances and numerical models can help in disregarding potential sources or accounting for new ones. In any case, a preliminary conceptual model is needed to identify potential end-members and to get preliminary values of the overall groundwater balance.

A significant proportion of recharge water may come from losses of the water supply and sewer networks. Leaks and broken pipelines cause significant water losses in many places. Accurate location of these leaks is not possible with the proposed methodology, unless an unrealistically dense groundwater observation network is implemented. However, we argue that overall estimates of leaks can be obtained. In any case, it is clear that (1) these two sources should always be taken into account, and (2) there is a great potential for interaction between the methodology presented here and the management of water networks.

\subsection{Tracer selection}

Selecting appropriate tracers is a critical step in mixing calculations (Dassargues, 2000; Barrett et al., 1999; Yang et al., 1999; Choi et al., 2005; Verstraeten et al., 2005; Morris et al., 2006). Ideally, tracers should be conservative, inexpensive and easy (fast) to analyze with accuracy. Also, their concentrations should vary widely from one source to another. Again, one needs a preliminary hydrochemical conceptual model to guess which species might be most helpful.

While not all methods used for evaluating recharge in natural systems can be extended to urban systems, the use of natural or anthropogenic environmental tracers is perhaps one of the best alternatives for both cases. Many authors compare solute concentrations in urban and rural areas (Barrett et al., 1997, 1999). Major ions, specially those conservative as halogens (especially $\mathrm{F}$ and $\mathrm{Br}$ ), Boron, EDTA (indicative of sewage water) or Zinc (indicative of urban runoff) are sometimes suggested (Carrera, 1997; Trauth and Xanthopoulos, 1997; Adar and Nativ, 2003; Dahan et al., 2004; Wolf et al., 2004; Morris et al., 2006; Osenbruck et al., 2007). Another option is the use of combinations of species that remain unaffected by reactions. An example of these is residual alkalinity (RA), defined as Alk+[F] $]_{\mathrm{T}}-[\mathrm{Ca}]_{\mathrm{T}}$, where Alk is alkalinity, and $[\mathrm{F}]_{\mathrm{T}}$ and $[\mathrm{Ca}]_{\mathrm{T}}$ are the total concentrations of $\mathrm{F}$ and $\mathrm{Ca}$ (that is, including ionic species and all their compounds). RA is unaffected by calcite or fluorite dissolution or precipitation (Barbiero et al., 2001). Nitrate contamination could be assessed by the use of nitrogen compounds regarless the nitrogen isotope (Rivers et al., 1996; Barrett et al., 1999; Katz et al., 2004; Drake and Bauder, 2005; Wakida et al., 2005; Wakida and Lerner, 2005; Vertraeten et al., 2005; Taylor et al., 2006; Corniello et al., 2007). Microbiological tracers have been proposed to assess recharge by contaminated waters related to sewer water, landfills, runoff, etc. (Cronin et al., 2003; Powel et al., 2003; Paul et al., 2004; Vertraeten et al., 2005; Morris et al., 2006). Contaminated waters can also be identified by means of organic compounds, BTEX, PAH, metabolites, pharmaceuticals, etc. (Wolf et al., 2004; Verstraeten et al., 2005; Osenbruck, 2007). Dating tracers (e.g., Radioactive Isotopes, SF6, CFC, ${ }^{3} \mathrm{H}-\mathrm{He}$ ) have been 
used to assess recent recharge in urban areas (Bauer et al., 2001; Morris et al., 2006). Environmental isotopes, notably ${ }^{18} \mathrm{O}$ and ${ }^{2} \mathrm{H}$, meet most requirements for ideal tracers. Moreover, marked isotopic signatures may be expected whenever supply water is brought from far away or when river recharge is significant. Therefore, they are widely used (Butler and Verhagen, 1997; Vázquez-Suñe et al., 2000; Adar and Nativ, 2003; Katz et al., 2004; Wakida et al., 2005; Verstraeten et al., 2005; Choi et al., 2005; Morris et al., 2006; Taylor et al., 2006; Osenbruck et al., 2007; Rueedi et al., 2007).

Most of the above tracers cannot be used uncritically. Their behavior may depend on local geochemical conditions (e.g. nitrate would not be conservative in reducing environments). Moreover, many of them help in identifying a source, but may be ambiguous (e.g, the presence of EDTA ensures mixing with waste water, but its absence does not ensure the opposite). In short, a prior conceptual model is required both for an assessment of geochemical conditions and for guessing which tracer might display a broadest range of concentration among end-members.

\subsection{Basic methodology}

Mixing ratios are computed using the approach of Carrera et al. (2004), which is an extension of the one by Kent et al. (1990). For completeness a summary of the methodology is presented. In essence, it is assumed that the concentrations of $n s$ species are known at $n p$ points. These concentrations result from conservative mixing of $n e$ end-member sources. Mixing equations can be written in matrix form as:

$\mathbf{Y}=\mathbf{X} \Delta+\varepsilon$

where $\mathbf{Y}$ is a $n s \times n p$ matrix, whose columns are the concentrations of all species at each sample, $\mathbf{X}$ is a $n s \times n e$ matrix containing the $n s$ concentration in each end-member, $\Delta$ is a $n e \times n p$ matrix containing the mixing ratios of each endmember in each sample point, and $\varepsilon$ contains the $n s \times n p$ measurement errors. Mixing ratios must add up to 1 and be positive, That is:

$0 \leq \delta_{\mathrm{pe}} \leq 1 \quad p=1, \ldots n p: e=1 \ldots n e$

$\delta_{\mathrm{p}}^{\mathrm{t}} 1_{n e}=1 \quad p=1, \ldots, n p$

where $\delta_{p e}$ is the pe component of $\boldsymbol{\Delta}$, and $\boldsymbol{\delta}_{p}$ its $p$-th column, that is a ne vector containing the proportions in which the end-members are mixed in the $p$-th sample.

Least squares allows easy computation of mixing ratios when end-members concentrations are assumed known. In fact, assuming that measurement errors are independent at each sample, $p$, least squares, constrained by Eq. (3) yields:

$$
\left(\boldsymbol{X}^{t} \boldsymbol{V}_{\mathrm{p}}^{-1} \boldsymbol{X}\right)_{x} \delta_{\mathrm{px}}=\left(\boldsymbol{X}^{\mathrm{t}} \boldsymbol{V}_{\mathrm{p}}^{-1} \boldsymbol{y}_{\mathrm{p}}\right)_{x}
$$

$\mathbf{y}_{p}$ is the $p$-th column of $\mathbf{Y}$, that is, a vector of dimension $n s$ containing the measured concentrations of all species at the $p$-th sample (the components of the vector are denoted by $\mathbf{y}_{\mathrm{ps}}$ ), and $\mathbf{V}_{\mathrm{p}}$ is the covariance matrix of sample measurement errors, taken hereinafter as diagonal. Subindex $x$ stands for extended, which is required for satisfying constraint (Eq. 3). It consists of adding a row and a column of 1's to $\mathbf{X}^{t} \mathbf{V}_{\mathrm{p}}^{-1} \mathbf{X}$ and a 1 to the rhs vector. The vector of unknowns, $\boldsymbol{\delta}_{p x}$ consists of $\delta_{\mathrm{p}}$ and a Lagrange multiplier in the last component. Since both constraints and the least squares objective function are convex, constraints (Eq. 2) are imposed by setting to zero the mixing ratios that become negative in the solution of (Eq. 4), and repeating the computation until convergence in an iterative process.

These equations are relatively straight-forwards to solve. Unfortunately, end-member concentrations can be highly uncertain. They also need to be estimated. Joint estimation is formulated in a maximum likelihood framework. Assuming multigaussianity, this leads to

$\ln L=-(\mathbf{Z}-\mathbf{M})^{\mathrm{t}} \mathbf{V}^{-1}(\mathbf{Z}-\mathbf{M})$

where $\mathbf{Z}^{\mathrm{t}}=\left(\mathbf{X}^{\mathrm{t}}, \mathbf{Y}^{\mathrm{t}}\right)$ is the matrix $((n e+n p) \times n s)$ of all concentration data, $\mathbf{M}^{\mathrm{t}}=\left(\mathbf{M}_{x}^{\mathrm{t}}, \mathbf{M}_{y}^{\mathrm{t}}\right)$ contains their expectations (problem unknowns) and $\mathbf{V}$ their covariance matrix. The likelihood (Eq. 5) is maximized with respect to $\mathbf{M}$ and $\boldsymbol{\Delta}$, which must satisfy the constraints (Eqs. 3 and 4), as well as

$\mathbf{M}_{y}=\mathbf{M}_{x} \boldsymbol{\Delta}$

which results from taking expectations in Eq. (1). Details of the algorithm are discussed by Carrera et al. (2004).

As mentioned in the introduction, the above formulation suffers from identifiability and colinearity. The risk of colinearity can be assessed by analyzing the system (Eq. 4). Specifically, unidentifiability is associated to the smallest eigenvalues of $\boldsymbol{B}_{\mathrm{p}}=\left(\boldsymbol{X}^{\mathrm{t}} \boldsymbol{V}_{\mathrm{p}}^{-1} \boldsymbol{X}\right)_{x}$. The combinations that cannot be identified are given by the corresponding eigenvector.

Notice that the eigenanalysis of $\mathbf{B}_{\mathrm{px}}$ is radically different from that of EMMA (Hooper et al., 1990), which aims at identifying the minimum number of end-members required to explain the variability of measured concentrations. Here, instead, we aim at stating whether mixing ratios can be computed from a priori defined end-members. As such, our eigenanalysis is specific for each sample, $p$, and depends on (1) actual colinearity of end-member concentrations $\mathbf{X}$, (2) prescribed mixing ratios, and (3) the variances of measurement errors $\mathbf{V}_{\mathrm{p}}^{-1}$. Regarding the first, note that if $\mathbf{X}$ is not full ranked (or nearly so), then $\mathbf{B}$ will not be full ranked either. Moreover, effective colinearity may result from large measurement errors. If measurement errors at a given sample are larger than the range of end-member concentrations, then mixing ratios cannot be estimated accurately.

To reduce the effect of co-linearity, one would have to increase the number of analyzed species. Given that this is not possible, there are two options: 
1. Eliminate one or several end-members. This is a reasonable option when colinearity is observed on the raw end-members concentrations. This is identified by unduly small eigenvalues of $\mathbf{X}^{\mathbf{t}} \mathbf{X}$. In such cases, colinearity implies that one of the end-members is a linear combination of the others. Therefore, from a mathematical viewpoint, nothing is lost by eliminating it. From a practical viewpoint, the modeler should be aware that data are ambiguous regarding the mixing ratios of the involved end-members.

2. Reduce the number of unknowns by fixing one or several mixing ratios. This is a frequent option in cases where it is clear that a given end-member cannot be present in a specific sample. For example, in the case of Barcelona, it is clear that sea-water cannot be found at high elevations or Besòs River water cannot be found in the samples taken southwest of the city. Therefore, some mixing ratios can be set to zero at selected wells.

The algorithm described above, including eigenanalysis and prescribing mixing ratios of some end-members. The resulting code (MIX2), including input data description and examples (in particular that presented in this paper), can be downloaded from http://www.h2ogeo.upc.edu/software/ MIX_PROGRAM/index.htm.

\subsection{Synthesis of results, discussion and iteration}

Mixing ratios derived from the above steps are representative of the analyzed samples and incorporate some degree of uncertainty. Drawing conclusions from such mixing ratios requires a synthesis effort. The analysis of results may point to the need for new sources of recharge or new tracer species. The conceptual model may need a revision, so that all steps may have to be repeated.

In our experience, results are quite robust when (1) endmember concentrations span a broad interval and they are not co-linear, (2) the chosen tracers are indeed conservative, and (3) their number is much larger than the number of potential sources. Otherwise, results will be sensitive to input assumptions. In this case, care must be exerted on how to define the standard deviations $\sigma_{\mathrm{su}}$ for each species, $s$, in each analysis $u$ ( $u=e$ for end-members, and $u=p$ for mixtures). The computed mixing ratios are not sensitive to the absolute value of $\sigma_{\mathrm{su}}$, but may be sensitive to their relative values. Therefore, consistency may be critical. We typically define $\sigma_{\mathrm{su}}^{2}=\left(v_{\mathrm{su}}^{2}+\tau_{\mathrm{sut}}^{2}\right) f_{\mathrm{u}}$, where

- $f_{\mathrm{u}}$ is a sample or end-member dependent factor. By default it should equal 1. But may be different for singular cases. For example, seawater is well known, so that its concentration $s$ will generally be much less uncertain than those of other end-members. A large $f_{\mathrm{u}}$ may be applied to a well suspected of point pollution.
- $v_{\mathrm{su}}$ is basically a species dependent factor that represents mainly analytical errors, but may also reflect uncertainties on the behavior of species. We usually adopt a multiplicative factor for most ions (e.g., $v_{\text {sn }}$ equal to $20 \%$ of measured concentration for $\mathrm{Cl}^{-}$), but a constant value for isotopes (e.g., $v_{\mathrm{sn}}=5$ for $\delta^{18} \mathrm{O}$ ).

- $\tau_{\text {su }}$ is used to account for time variability, which may be required for end-members. For example, river water concentrations may fluctuate significantly, so that the average concentration may not be representative of river recharge. This uncertainty can be acknowledged by setting $\tau_{\mathrm{su}}$ to the standard deviation of time fluctuations of species $s$ at end-member $e$.

\section{Application to the Barcelona city urban aquifers}

In this section we outline the application of the above methodology to the urban aquifers located beneath Barcelona.

\subsection{Conceptual model: potential recharge sources}

Barcelona is located in north-eastern Spain, between the Serra de Collcerola and the Mediterranean Sea (see Fig. 2), both boundaries running approximately NNE-SSW. The other boundaries are two rivers, Llobregat (to the SW) and Besòs (NE). Together, they yield a rectangle that slopes gently to the sea. Some hills break this plain, forming local steep slopes that give rise to some streams, most of them presently urbanised. Several aquifers, characterised by their geological age, can be seen in Fig. 2.

The Paleozoic aquifer outcrops at the topographic heights located NW. It consists of shales and granites, yielding some water from both wells and ancient khanats (infiltration galleries). Quaternary aquifers can be found in the rest of the city. In topographic low areas, they correspond to the alluvial and deltaic sediments of the Llobregat and Besòs rivers. In intermediate areas, they correspond to piedmont cones and to coarse alluvial sediments.

The Barcelona aquifers have supported heavy water extraction since the mid XIXth Century. Pumping was particularly intense at the two deltaic aquifers. Extraction produced large drawdowns, leading to seawater intrusion. Since the 1970's, urban pressures have caused many industries to migrate away from the city. This resulted in a reduction of pumping and a progressive recovery of heads (Vázquez-Suñé et al., 2005b).

Direct rainfall recharge occurs at the non-urbanized areas in the NW heights. This is considered "clean" natural recharge water. Seawater intrusion and water from the rather polluted Besòs River must be considered potential recharge sources in low areas. Additional sources of groundwater recharge can be attributed to anthropic actions related to city development. The first one is losses in the supply 


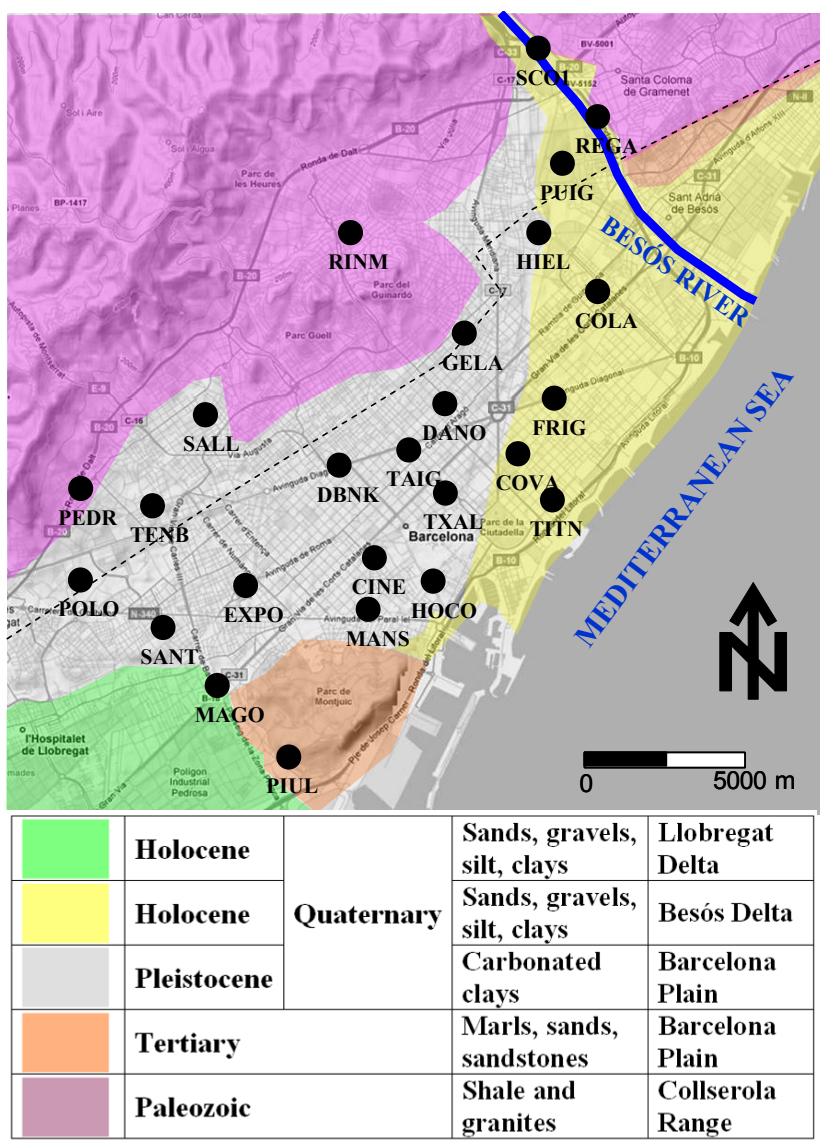

Fig. 2. Schematic description of the hydrogeology of Barcelona. The dashed line represents the boundary between Paleozoic and tertiary materials. Sampling points are identified by a black dot and a label.

network. Supply to Barcelona comes from the Ter and Llobregat rivers. This causes a separation of the city into two zones with distinct water quality. As a consequence of the two different origins of the supply water, two different chemical compositions can be found in waste water. Finally, in paved areas, runoff water washes the road and atmospheric deposition and recharges the aquifers through direct infiltration or sewers losses. In summary, we have identified up to eight different recharge sources in the city: (1) Besòs river (RIV), (2) rainfall recharge in northern non urban area (REC), (3) Ter river water supply (TER), (4) Llobregat river water supply (LLOB), (5) Ter river sewage water (SW_TER), (6) Llobregat river sewage water (SW_LL), (7) City runoff (RUNOFF), and (8) Sea water intrusion (SEA).

\subsection{Tracer selection}

All potential recharge sources have been sampled for chemical and isotopic analysis. These analyses include main ions, microbiologic indicators, halogens, heavy metals, EDTA, and isotopes: ${ }^{34} \mathrm{~S},{ }^{18} \mathrm{O}$ and Deuterium (D). A historical record is available for some of these sources. Moreover, up to 30 wells distributed throughout the city have been analyzed every three months between 1988 and 2009, so that a large chemical database is available.

Preliminary inspection of these data and experience (recall Sect. 2.2) suggest the use of 12 chemical species in the analysis of mixing ratios: $\mathrm{Cl}, \mathrm{SO}_{4},{ }^{34} \mathrm{~S}, \mathrm{~B}, \mathrm{~F}, \mathrm{Br}$, EDTA, $\mathrm{Zn},{ }^{18} \mathrm{O}$, $\mathrm{D}$, Total Nitrogen $(\mathrm{N})$ and Residual Alkalinity (RA). These species combined allow discriminating quite well the major sources of recharge.

Some of the analyzed species appear to be non conservative. For example, EDTA measured concentrations in the water coming from wells were very low compared to those in end-members. This suggests that EDTA, coming mainly from sewage, sorbs or degrades in the aquifer, which is indeed the case for most sewage water organic pollutants. To address this uncertainty, mixing ratios have been computed both considering and not considering these questionably conservative species: one run was performed with only 8 species $\left(\mathrm{Cl}, \mathrm{SO}_{4},{ }^{34} \mathrm{~S}, \mathrm{~F}, \mathrm{Br},{ }^{18} \mathrm{O}, \mathrm{D}\right.$ and $\left.\mathrm{N}\right)$ and another with the full set of 12 species. Results are presented later.

\subsection{Groundwater sampling point selection and data treatment}

Samples come from direct pumping of wells and piezometers. Pumped volume prior to sampling was equal to at least three times the volume of water in the well. Samples were taken in several bottles with additives depending on the species to be analyzed (acidifiers for metals, formaldehyde for EDTA, etc.). The bottles were stored in a field refrigerator and taken to the laboratory at the end of the sampling day.

Most species were analyzed at the laboratory of the Public Health Agency of Barcelona. $\mathrm{Cl}, \mathrm{SO}_{4}$ and $\mathrm{N}$ species were analyzed by ionic chromatography, basic cations and trace metals were analyzed by ICP-AES. ${ }^{18} \mathrm{O}$ and D were analyzed at the Bureau of Stable Isotope Analysis (BSIA) of UK. ${ }^{34} \mathrm{~S}$ was analyzed by duplicate at the University of Barcelona (UB) using the methodology described by Otero and Soler (2002). $\mathrm{Br}$ and $\mathrm{F}$ were analyzed with a ion selective electrode and $\mathrm{B}$ by ICP at the University of Barcelona Scientific and Technical Services. EDTA was analyzed by cCG-NPD at CIDCSIC (Barcelona).

The proportions of each source in each well may change with time in response to changes in flow directions. By using concentrations at a sample, we are seeking the mixing ratios of that sample. Since mixing is linear, we could as well work with time averaged concentrations; to obtain time averaged mixing ratios. Actually, most wells display rather constant species concentrations. We opted for restricting the study to a single campaign because analyses of some species were missing for some campaigns, which would have required increasing the standard deviations of those species. 

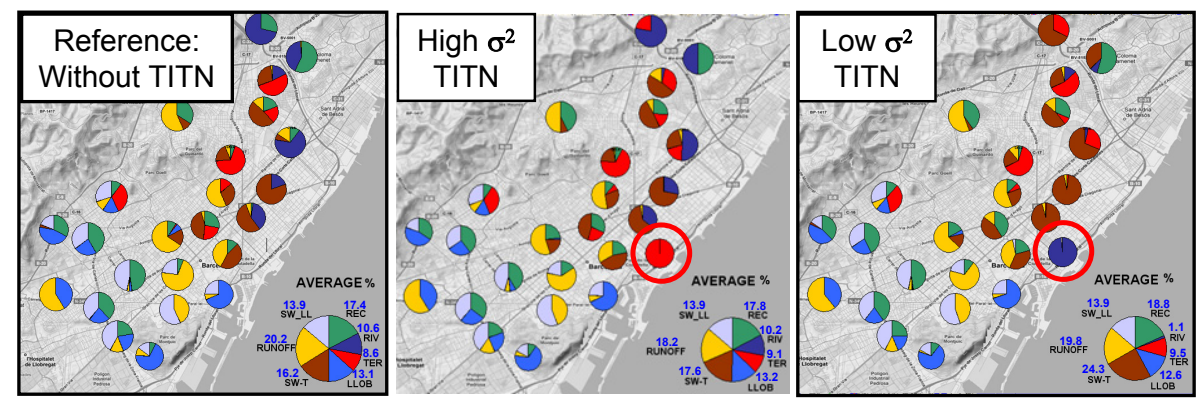

Fig. 3. Sensitivity of mixing results to the treatment of an outlier (TITN, identified with a red ring in the center and left plots). All computations are performed with 12 species, 24 or 25 wells and 8 recharge sources. Results obtained omitting the TITN well (left) are similar to those obtained assigning a very large variance to this well (center), except for TER supply water. But they are very different from the results obtained with low (same as Frigo well) variance, shown in the right graph. TITN well is not considered for the average calculations.

The May 1999 campaign, with 25 wells, has been used (see Fig. 2 for location of the sample points).

Standard deviations were handled a discussed in Sect. 2.4. For some of the species, the conceptual model is uncertain (i.e. other point sources, contamination, red-ox processes, etc.). In these cases, the standard deviation has been increased.

Actually, only one of the observation network well displayed signs of pollution (TITN). We used it to illustrate the options to handle outliers. We know of other point pollution sites (mostly in the former industrial area in the Besòs Delta), but the contamination does not extend far, probably because of natural attenuation. In this regard, one should bear in mind that Barcelona is a very "urban" city (i.e., largely residential and business offices, but little industry within the city). We did find TCE in several wells, which probably reflect point pollution, but we did not use it as one of the tracers, because we do not know the strength of the source. The summary of this discussion is that point sources are not significant volumetrically, although they may affect water quality.

The resulting concentration data and the standard deviations adopted for all wells and end-members can be found as one of the examples of the MIX2 documentation that can be downloaded from http://www.h2ogeo.upc.edu/software/ MIX_PROGRAM/index.htm.

\section{Results and discussion}

Both methodological and urban recharge conceptual issues are discussed below.

\subsection{Outliers}

Outliers may affect negatively the whole estimation process by forcing estimated concentrations to fit erroneous data. Outliers can be identified by their contribution to the objective function. In our case, the TITN well contributed initially
14\% (since 25 well samples, plus 8 end-members are available, each should contribute $3 \%$ on average). Close examination of data from this well showed that it is affected by local industrial pollution, leading to heavily reduced redox conditions. As a result, the assumption of conservative mixing was not valid at least for $\mathrm{SO}_{4}, \mathrm{NO}_{3}$ and ${ }^{34} \mathrm{~S}$ at this well.

Two alternative actions can be adopted to deal with outliers. One can either eliminate them from the data base, thus eliminating their potentially damaging effect on the estimation process. Another option is to reduce their weight (i.e. increase artificially the standard deviation assigned to measurements). The latter option is less dramatic than the former and may be preferable when the reasons for the problems are not clear and may be fixed later when the conceptual model is refined. For example, if several outliers are present, keeping them with high measurement variances may help in identifying a missing end-member. As shown in Fig. 3, both options affect the overall estimation in a similar way. In what follows, we have eliminated data from TITN well.

\subsection{Identifying colinearity}

As stated in Sect. 2, the estimation can be quite unstable whenever the number of sources is high (as compared to the number of conservative species). In such cases the user must take some steps that lead to stable and reasonable values of mixing ratios. In our case, we performed a preliminary run of the code to see if we got conceptually consistent results. We did not. For example, some wells in the Barcelona plain contained Besòs river water, which is not possible. Also, some wells contained supply water from one source (e.g., Llobregat), but waste water from another (e.g., Ter), which is unplausible. The problem lies in the high number of endmembers relative to conservative tracers. This causes the estimation problem to be unstable. This is why we had to modify the code to allow setting some mixing ratios to zero, as a way of stabilizing the problem. 

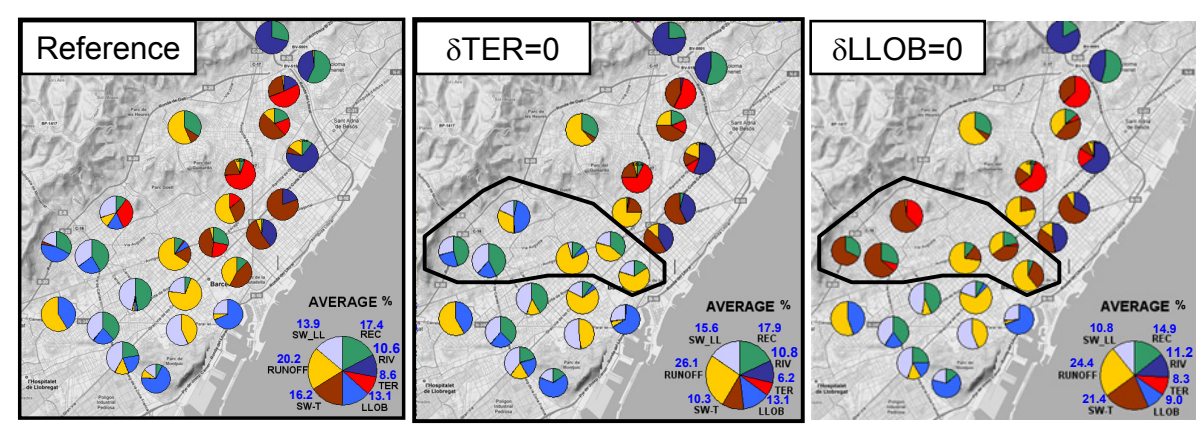

Fig. 4. Sensitivity of mixing results in the case of linear combination for all species in some end-member waters. All computations are performed with 12 species, 24 wells and 8 recharge sources. Results display the mixing ratios computed by (1) center: fixing the mixing ratios of TER and SW_TER to zero at the wells located in this area, (2) right: fixing LLOB and SW_LLOB to zero, and (3) left: not fixing them.

In order to identify and fix this type of problems, the first step is to perform an eigenanalysis. In our case, a very low eigenvalue is associated to the eigenvector: $\boldsymbol{V}=\mathrm{SW} \_\mathrm{TER}-\mathrm{TER}-\mathrm{SW} \_L L+$ LLOB . Conceptually, this low eigenvector implies that the above linear combination is close to zero for all species in the end-member waters. This reflects that the increase in concentrations caused by human use (i.e. the difference between waste and supply water) is similar when the supply water comes either from the Ter River (SW_TER - TER) or the Llobregat River (SW_LL - LLOB). This explains some of the inconsistent results we got in the above preliminary runs. Actually, we had hoped that isotopic signatures would have allowed this distinction, but they are not sufficiently different.

Since the data does not allow distinguishing these sources, one needs to resolve the problem conceptually (i.e., using independent data). In this case, the southern part of the city is generally supplied by LLOB water, so that mixing ratios for TER and SW_TER can be fixed a priori to zero. The opposite is true for the northern part of Barcelona. However these two areas are not closed, and in the middle part of the city a mixture of the two supply waters may occur.

This is illustrated by Fig. 4, which displays the mixing ratios computed by (1) fixing the mixing ratios of TER and SW_TER to zero at the wells located in this area (wells DBNK, PEDR, SALL, TAIG, TENB, and TXAL), (2) fixing LLOB and SW_LLOB to zero, and (3) not fixing them. It is clear that the changes in mixing ratio estimations are largely restricted to these wells, which suggest that the estimates are quite robust.

\subsection{Include or eliminate doubtful species}

A choice should be made whether it is more appropriate to use a large set of chemical species, including some that may not be conservative, or a smaller number of more reliable species. Ratios obtained using 8 and 12 species are shown in Fig. 5. Results are similar in terms of average mixing
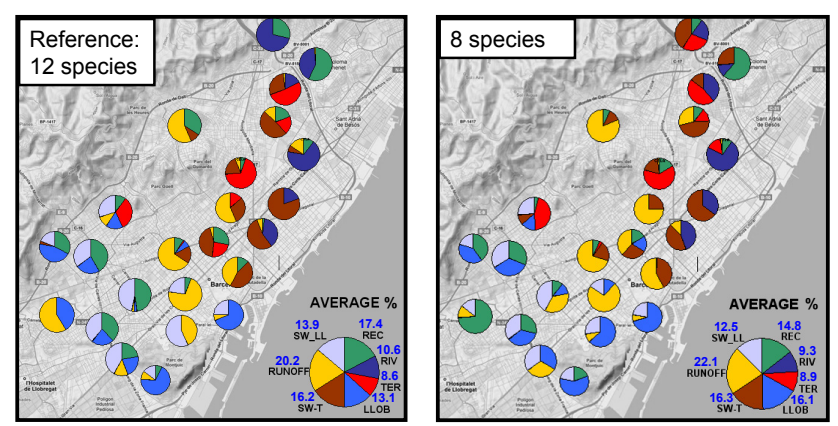

Fig. 5. Comparison of mixing results obtained using 24 wells and 8 recharge sources and either 12 (left) or 8 (right) species. Results are similar for large portions of the aquifer. However, the mixing ratios for northern wells are significantly different. Results of the left plot are more consistent with our conceptual model, despite the fact that the four additional species display non-conservative behavior.

ratios, but quite different in the local estimates. Careful analysis suggests that, in this case, the results obtained with 12 species are more realistic. For example, well SCO1 located north and assumed to be basically fed by Besòs River water (RIV) and recharge (REC) water, yields significant proportions of TER water, when only 8 species are used. Therefore, we have opted for working with the full set of 12 species.

\subsection{Reliability of end-member concentrations}

Mixing ratios are very sensitive to errors in end-member concentrations. The need to account for uncertainty in endmember concentrations is best illustrated by the plots of measured concentrations (Fig. 6).

Measured end-member concentrations fail to envelope measurements of mixtures samples, indicating, first, that end-member concentrations need to be corrected. The inconsistency of measurements implies that mixing calculations 

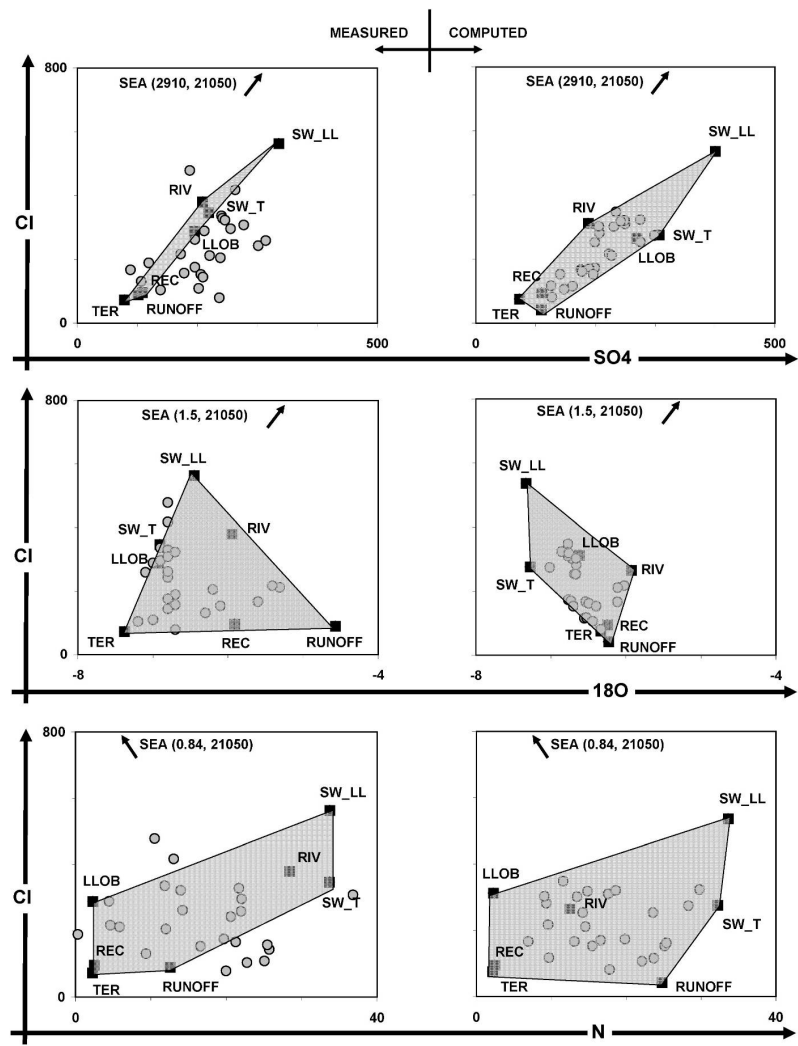

SOURCES OWELLS
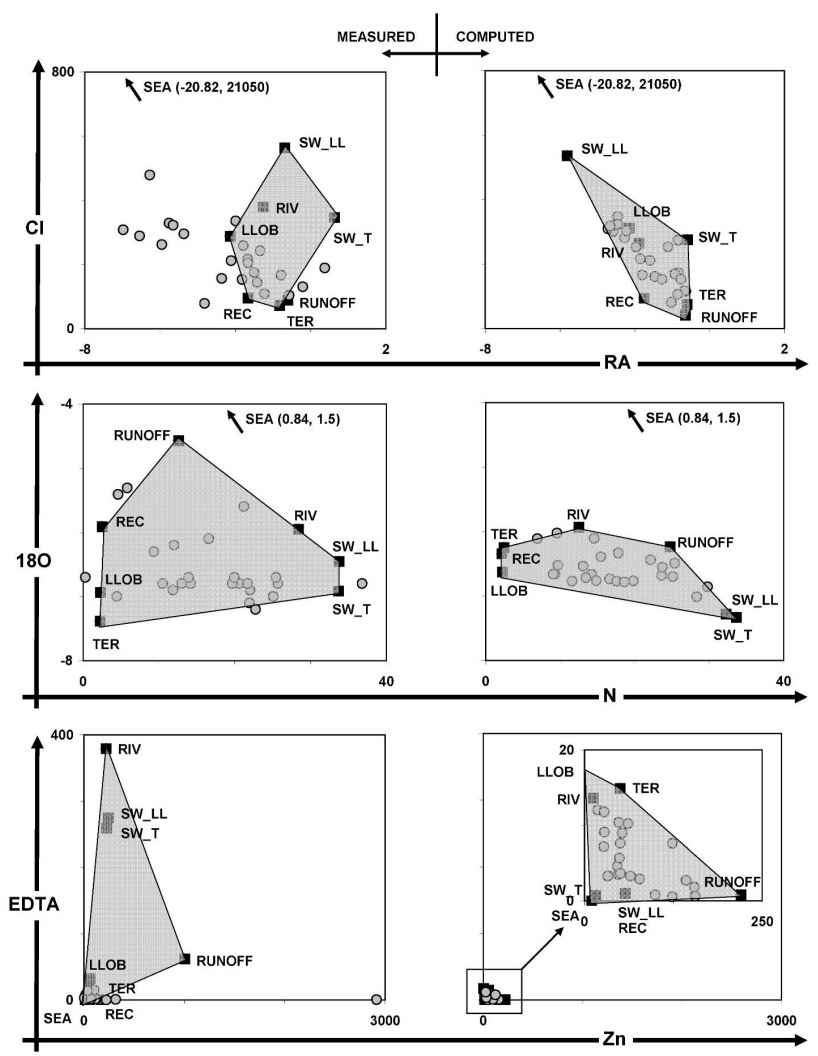

Fig. 6. Plots of both measured and computed concentrations. Notice that measured concentrations of end-members fail to envelope computed concentrations in several plots (notably $\mathrm{Cl}$ vs. $\mathrm{SO}_{4}, \mathrm{Cl}$ vs. N, Cl vs. RA). Obviously, computed end-members should encircle the computed concentrations.

could not be carried out with the original data, hence the need for the approach proposed here. However, a question arises regarding these inconsistencies, which are too large to be due solely to measurement errors. Three options can be considered: (1) some unknown end-member is missing, (2) the chosen species are non-conservative, or (3) the adopted values for end-member concentrations are not representative.

The discussion of which option is most realistic can be best carried by comparing measured and computed concentrations. These are shown in Fig. 7, which allows identifying the end-members that fall furthest away from the 1:1 line. Several observations can be made:

- Computed concentrations of chloride and nitrate at the river are significantly lower than their measured values. This result may reflect that actual recharge concentrates during floods, when river water is most diluted.

- On the other hand, total nitrogen $(\mathrm{N})$ in runoff is significantly increased. Runoff $\mathrm{N}$ is mostly ammonia, from atmospheric $\mathrm{NH}_{3}$ coming from organic fertilizers around the city, and $\mathrm{NO}_{\mathrm{x}}$ from combustion engines (Querol et al., 2008; Pérez et al., 2008). The concentration of $\mathrm{N}$ in these two sources is highly variable in space and time.
- EDTA is often purported to be highly conservative. Figure 6 suggests otherwise. Most EDTA from sewage water and runoff seems to have disappeared, perhaps sorbed into particles that are filtered by the soil. The same can be said about $\mathrm{Zn}$.

\subsection{Spatial distribution of mixing ratios}

The most conceptually relevant results in this example are the spatial distribution of mixing ratios (recall Figs. 4 and 5). Computed mixing ratios display significant variability, but several trends can be observed. First, most samples contain significant portions of water coming from both supply and sewage networks. These two sources account for some $50 \%$ of the resident water in the aquifer. This may sound surprising. It should be noticed, however, that (1) the city imports some $200 \mathrm{MCM} / \mathrm{yr}$ for supply, while rainfall amounts to $5 \mathrm{MCM} / \mathrm{yr}$ (a recharge of $50 \mathrm{~mm} / \mathrm{yr}$ ), only $2.5 \%$ of the supply inflow; (2) some of the sewage network is quite old, and (3) until recently, a portion of the street cleaning and park irrigation was carried out with supply water.

Stormwater runoff recharge is highly variable, ranging from well over 50\% at the POLO, CINE, DBNK, DANO, 


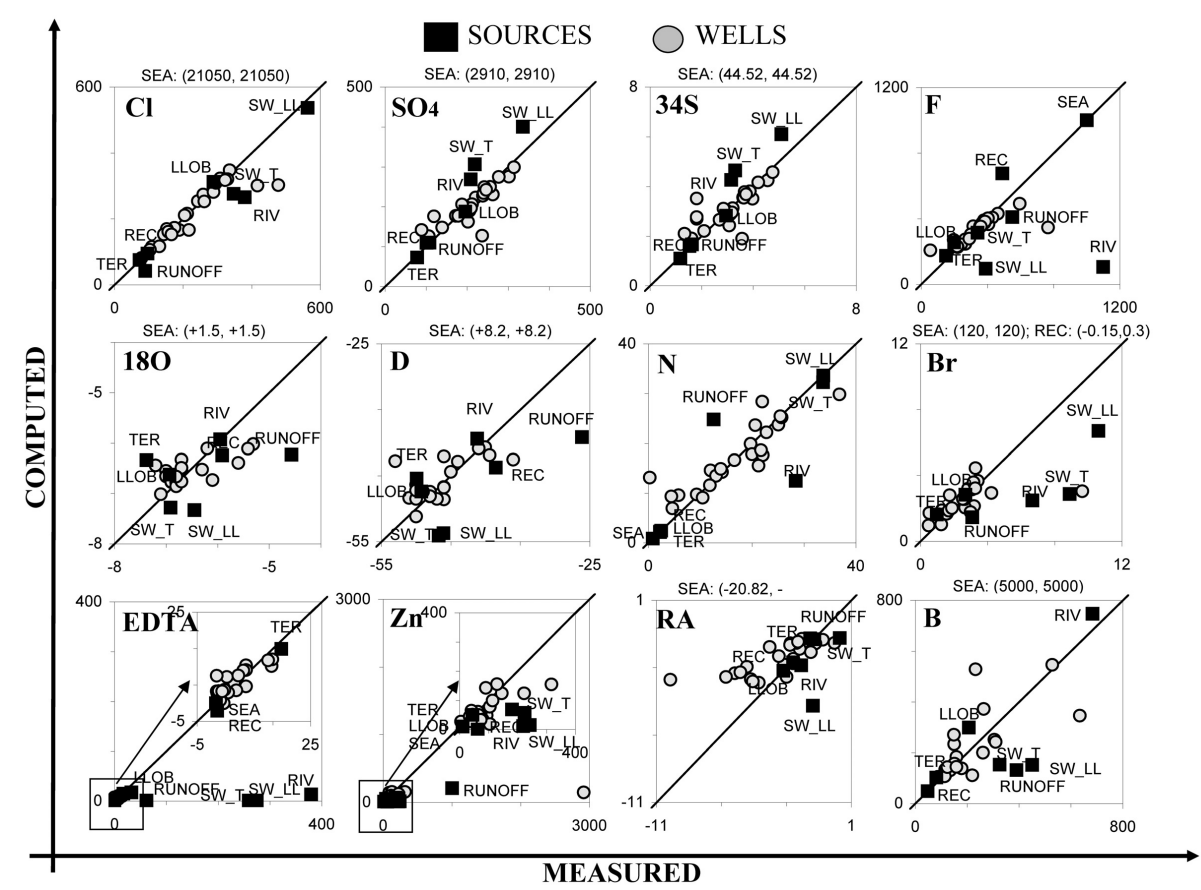

Fig. 7. Computed vs. measured concentrations of all species at all end-members and well samples. Notice the significant reductions of $\mathrm{Cl}$, $\mathrm{F}, \mathrm{N}, \mathrm{Br}$ and EDTA concentrations at the river end-member, which probably reflects the fact that river recharge occurs mainly during floods. Notice also the non conservative behavior of EDTA (end-member concentrations need to be drastically reduced), RA (mixed samples RA need to be increased) and, to some extent, $\mathrm{Zn}$ and $\mathrm{B}$.

MANS and RINM wells to nearly zero at most wells. Overall, stormwater recharge represents about $20 \%$ of the resident water. This low number probably reflects the sloping landscape of Barcelona (water does not pond) and the fact that no active storm water recharge plans were active until recently.

Computed concentrations of most species for Besòs river recharge are significantly smaller than our measurements, which come from long term averaging. Probably recharge increases significantly in higher river flow rates events, when solutes are most diluted (Vázquez-Suñé et al., 2007).

The use of these results is not straightforward. On one hand, they reflect resident water concentrations and mixing ratios. These values are important by themselves, since they provide information about how water can be exploited, but cannot be used as indicators of the relative importance of the recharge sources. To do so, a full groundwater flow and transport model is needed. To illustrate this point, let us consider a case where clean natural recharge water is infiltrated from the upstream edge of the aquifer while wastewater is recharged in the lowest part. A large percentage of natural recharge water over most of the area would simply reflect the most wastewater enters in the lowest portion of the city. The average mixing ratios may fails to indicate overall recharge ratios.

Time variations are expected on several scales. They reflect changes in the composition of end-members (because of changes in water use, infrastructures, etc.) and in the mixing ratios (because of the movement of water bodies). As it turns out, what we observe is that ground water composition in Barcelona did not change significantly in our campaigns, except in the vicinity of areas where sources of recharge can change significantly in volume and composition. This is the case of the Besòs River area, where seasonal variations reflecting the seasonal changes in river water quality can also be observed in the aquifer. Nonetheless, we can observe long term variations when comparing to old analyses. Fluctuations are much larger in the composition of all end-members, including supply water. For the sake of consistency, we opted for restricting the study to a single campaign. At present we are working on different applications in the urban area of Barcelona. One of them is the estimation of sources proportion variation in the vicinity of the Besòs River due to the river recharge dynamics.

\section{Conclusions}

Recharge is often the most difficult term to evaluate in the hydrological cycle. This is especially true in urban environments. We have presented a methodology for quantifying the proportions in which recharge sources contribute to resident water. The method is based on the mass balance of solutes and accounts for the uncertainty of end-members. 
Estimations can be highly unstable whenever the number of potential recharge sources is high (comparable to the number of conservative species). Potential problems include:

- Colinearity prevents the estimation of some linear combinations of recharge sources. Colinearity can be identified by means of an eigenanalysis and fixed by constraining the mixing ratios at some samples (in one case, fixing to zero the proportion of sources that can be assumed absent at some wells).

- Outliers may also affect negatively the whole estimation process. They can be identified by their contribution to the objective function. Their negative effect can be reduced by either eliminating them from the estimation process or by artificially increasing their measurement error standard deviations.

12 chemical species have been used: $\mathrm{Cl}, \mathrm{SO}_{4},{ }^{34} \mathrm{~S},{ }^{18} \mathrm{O}, \mathrm{D}$, F, N, Br, EDTA, Zn, RA and B. All, but the last four, behaved in a conservative way. Measured EDTA at wells was much lower than at recharge sources, which suggest degradation. RA was much higher in wells, which may be linked to degradation of organic matter and soil buffering. Despite of these difficulties, computed mixing ratios were conceptually more consistent when the full set of species was used.

Mapping mixing ratios in wells yields clear insights on the overall distribution of recharge sources. Computed ratios are generally consistent with our conceptual model and resulting concentrations are quite close to measurements. This implies that results are satisfactory and that the methodology can be considered validated. However, it is clear that results would have been much more robust if the number of end-members had been smaller, which would have also simplified the estimation process.

The methodology presented can be useful to quantify the origin of recharge in urban areas. However, the transfer from mixing ratios to recharge ratios is not straight forwards. In general, a flow model will be required to properly account for spatial and temporal variations. A preliminary analysis (assuming the measured wells are representative of the behavior of the full aquifer) suggests that $22 \%$ of total recharge comes from the water supply network, $30 \%$ from wastewater, $17 \%$ from Rainfall recharge in northern non urban area, $11 \%$ from Besòs River, $20 \%$ from runoff infiltration, while seawater intrusion contribution is almost negligible. This has consequences in both the evaluation of groundwater balances and in identifying the potential quality of groundwater based upon the quality of water in the end-members (or recharge sources). This has important potential implications in groundwater management in urban areas.
Acknowledgements. This work has been done in the framework of a project supported by Ajuntament de Barcelona (Barcelona City Council) and Clavegueram de Barcelona (CLABSA). Also, has been partially financed by the projects 2009 SGR 103 and 2009 SGR 1057 from the Catalan Government.

Edited by: A. Guadagnini

\section{References}

Adar, E. and Nativ, R.: Isotopes as tracers in a contaminated fractured chalk aquitard, J. Contam. Hydrol., 65(1-2), 19-39, 2003.

Adar, E. and Neuman, S.: Estimation of spatial recharge distribution using environmental isotopes and hydrochemical data, 2. application to Aravaipa Valley in Southern Arizona, USA, J. Hydrol., 97(3-4), 279-302, 1988.

Adar, E., Neuman, S., and Woolhiser, D.: Estimation of spatial recharge distribution using environmental isotopes and hydrochemical data, 1. Mathematical-model and application to synthetic data, J. Hydrol., 97(3-4), 251-277, 1988.

AIH-GE: El Agua y la ciudad sostenible: Hidrogeología urbana, Serie: Hidrogeología y aguas subterráneas, No. 11, IGME, Madrid, 342 pp., 2004.

AWWA: http://www.awwa.org/Resources/WaterLossControl.cfm? ItemNumber $=47846 \& \&$ navItemNumber $=48155$, last access: 2 July 2010.

Barbiero, L., Valles, V., Regeard, A., and Cheverry, C.: Residual alkalinity as tracer to estimate the changes induced by forage cultivation in a non-saline irrigated sodic soil, Agr. Water Manage., 50(3), 229-241, 2001.

Barrett, M., Hiscock, K., Pedley, S., Lerner, D., Tellam, J., and French, M.: Marker species for identifying urban groundwater recharge sources: A review and case study in Nottingham, UK, Water Res., 33(14), 3083-3097, 1999.

Barrett, M., Lerner, D., Pedley, S., Hiscock, K., and Tellam, J.: The use of marker species to establish the impact of the city of Nottingham, UK on the quantity and quality of its underlying groundwater, in: Groundwater in the urban environment - Vol I - problems, edited by: Chilton, J., Processes and Management, 85-90, 1997.

Bauer, S., Fulda, C., and Schafer, W.: A multi-tracer study in a shallow aquifer using age dating tracers $\mathrm{H}-3, \mathrm{Kr}-85, \mathrm{CFC}-113$ and SF6 - Indication for retarded transport of CFC-113, J. Hydrol., 248(1-4), 14-34, 2001.

Bickle, M., Chadwick, A., Huppert, H. E., Hallworth, M., and Lyle, S.: Modelling carbon dioxide accumulation at Sleipner: Implications for underground carbon storage, Earth Planet. Sc. Lett., 255(1-2), 164-176, 2007.

Blackwood, D., Ellis, J., Revitt, D., and Gilmour, D.: Factors influencing exfiltration processes in sewers, Water Sci. Technol., 51(2), 147-154, 2005.

Butler, M. and Verhagen, B.: Environmental isotopic tracing of water in the urban environment of Pretoria, South Africa, in: Groundwater in the urban environment - Vol I - Problems, edited by: Chilton, J., Processes and Management, 101-106, 1997.

Carrera, J.: Observación y medida de la recarga (descarga) a partir de aguas superficiales y conducciones transferencias y fugas, in: La evaluación de la recarga a los acuíferos en la Planificación Hidrológica, AIH-GE, IGME, 229-245, 1997. 
Carrera, J., Vázquez-Suñé, E., Castillo, O., and Sánchez-Vila, X.: A methodology to compute mixing ratios with uncertain end-members, Water Resour. Res., 40(12), W12101, doi:10.1029/2003WR002263, 2004.

Chilton, J., Hiscock, K., Younger, P., Morris, B., Puri, S., Nash, H., Aldous, P., Tellam, J., Kimblin, R., and Hennings, S.: Groundwater in the urban environment: problems processes and management, 27th Cong. Int. Assoc. Hydrogeologists (IAH), 2127 September 1997, Nottingham, Balkema, Lisse, The Netherlands, 682 pp., 1997.

Chilton, J.: Groundwater in the urban environment: selected city profiles, Balkema, Lisse, The Netherlands, 341 pp., 1999.

Choi, B., Yun, S., Yu, S., Lee, P., Park, S., Chae, G., and Mayer, B.: Hydrochemistry of urban groundwater in Seoul, South Korea: effects of land-use and pollutant recharge, Environ. Geol., 48(8), 979-990, 2005.

Christophersen, N. and Hooper, R.: Multivariate-analysis of stream water chemical-data - The use of principal components-analysis for the end-member mixing problem, Water Resour. Res., 28(1), 99-107, 1992.

Christophersen, N., Neal, C., Hooper, R., Vogt, R., and Andersen, S.: Modeling streamwater chemistry as a mixture of soilwater end-members - A step towards 2nd-generation acidification models, J. Hydrol., 116(1-4), 307-320, 1990.

Corniello, A., Ducci, D., and Ruggieri, G.: Areal identification of groundwater nitrate contamination sources in periurban areas, J. Soil Sediment., 7(3), 159-166, 2007.

Cox, M. H., Su, G. W., and Constantz, J.: Heat, chloride, and specific conductance as ground water tracers near streams, Ground Water, 45(2), 187-195, 2007.

Cronin, A., Taylor, R., Powell, K., Barrett, M., Trowsdale, S., and Lerner, D.: Temporal variations in the depth-specific hydrochemistry and sewage-related microbiology of an urban sandstone aquifer, Nottingham, United Kingdom, Hydrogeol. J., 11(2), 205-216, 2003.

Dahan, O., McGraw, D., Adar, E., Pohll, G., Bohm, B., and Thomas, J.: Multi-variable mixing cell model as a calibration and validation tool for hydrogeologic groundwater modeling, J. Hydrol., 293(1-4), 115-136, 2004.

Dassargues, A.: Tracers and modelling in hydrogeology, IAHS Publ., 262, 363-369, 2000.

De Simoni, M., Sánchez-Vila, X., Carrera, J., and Saaltink, M. W.: A mixing ratios based formulation for multicomponent reactive transport, Water Resoure. Res., 43(7), W07419, doi:10.1029/2006WR005256, 2007.

Drake, V. and Bauder, J.: Ground water nitrate-nitrogen trends in relation to urban development, Helena, Montana, 1971-2003, Ground Water Monit. R., 25(2), 118-130, 2005.

Ellis, B.: Impacts of urban growth on surface water and groundwater quality, IAHS no. 259, IAHS, Wallingford, UK, 437 pp., 1999.

Eyles, E.: Environmental geology or urban areas, Geological Association of Canada, London, Spec. Publ. no. 3, 1997.

Hooper, R.: Diagnostic tools for mixing models of stream water chemistry, Water Resour. Res., 39(3), 1055, doi:10.1029/2002WR001528, 2003.

Hooper, R., Christophersen, N., and Peters, N.: Modeling streamwater chemistry as a mixture of soilwater end-members an application to the Panola mountain catchment, Georgia, USA,
J. Hydrol., 116(1-4), 321-343, 1990.

Howard, K. W. F. and Israfilov, R.: Current problems of hydrogeology in urban areas, urban agglomerates and industrial centres, Series IV: Earth and Environmental Sciences - Vol. 8, Kluwer Academic Publishers, Dordecht, 500 pp., 2002.

Hussein, M. and Schwartz, F.: Modeling of flow and contaminant transport in coupled streamaquifer systems, J. Contam. Hydrol., 65(1-2), 41-64, 2003.

IWA: http://www.iwahq.org/Home/Themes/Science_and_ application/, last access: 3 July 2010.

James, A. L. and Roulet, N. T.: Investigating the applicability of end-member mixing análisis (EMMA) across scale: A study of eight small, nested catchments in a temperate forested watershed, Water Resour. Res., 42(8), W08434, doi:10.1016/S01697722(02)00229-2, 2006.

Jones, J., Sudicky, E., Brookfield, A., and Park, Y.: An assessment of the tracer-based approach to quantifying groundwater contributions to streamflow, Water Resour. Res., 42(2), W02407, doi:10.1029/2005WR004130, 2006.

Katz, B., Chelette, A., and Pratt, T.: Use of chemical and isotopic tracers to assess nitrate contamination and ground-water age, Woodville Karst Plain, USA, J. Hydrol., 289(1-4), 61, 2004.

Kent, J., Watson, G., and Onstott, T.: Fitting straight-lines and planes with an application radiometric dating, Earth Planet. Sc. Lett., 97(1-2), 1-17, 1990.

Kim, Y., Lee, K., and Sung, I.: Urbanization and the groundwater budget, metropolitan Seoul area, Korea, Hydrogeol. J., 9(3), 401-412, 2001.

Lerner, D. N.: Recharge due to urbanization, in: Groundwater recharge, A guide to understanding and estimating natural recharge, edited by: Lerner, D. N., Issar, A. S., and Simmers, I., AIH, 210-214, 1990.

Lerner, D. N.: Guest editor's preface: theme issue on urban groundwater, Hydrogeol. J., 4, 4-5, 1996.

Llamas, R. and Custodio, E.: Intensive use of groundwater: Challenges and Opportunities, Balkema, Lisse, The Netherlands, 478 pp., 2002.

McLaughlin, K., Ahn, J. H., Litton, R. M., and Grant, S. B.: Use of salinity mixing models estimate the contribution of creek water fecal indicator bacteria to an estuarine environment: Newport Bay, California, Water Res., 41(16), 3595-3604, 2007.

Morris, B. L., Darling, W. G., Cronin, A. A., Rueedi, J., Whitehead, E. J., and Gooddy, C.: Assessing the impact of modern recharge on a sandstone aquifer beneath a suburb Doncaster, UK, Hydrogeol. J., 14(4), 979-997, 2006.

Neal, C., Jarvie, H. P., Wade, A. J., Neal, M., Wyatt, R., Wickham, H., Hill, L., and Hewitt, N.: The water quality of the LOCAR Pang and Lambourn catchments, Hydrol. Earth Syst. Sci., 8, 614-635, doi:10.5194/hess-8-614-2004, 2004.

Osenbrück, K., Glaeser, H.-R., Knoeller, K., Weise, S. M., Moeder, M., Wennrich, R., Schirmer, M., Reinstorf, F., Busch, W., and Strauch, G.: Sources and transport of selected organic micropollutants in urban groundwater underlying the city of Halle (Saale), Germany, Water Res., 41(15), 3259-3270, 2007.

Otero, N. and Soler, A.: Sulphur isotopes as tracers of the influence of potash mining in ground water salinisation in the Llobregat Basin (NE Spain), Water Res., 36(16), 3989-4000, 2002. 
Parkhurst, D. L. and Appelo, C. A. J.: User's guide to PHREEQC (version 2) - A computer program for speciation, batch-reaction, one-dimensional transport, and inverse geochemical calculations: U.S. Geological Survey Water-Resources Investigations Report 99-4259, 312 pp., 1999.

Paul, M., Wolf, L., Fund, K., Held, I., Winter, J., Elswirth, M., Gallert, C., and Hotzl, H.: Microbiological condition of urban groundwater in the vicinity of leaky sewer systems, Acta Hydroch. Hydrob., 32(4-5), 351-360, 2004.

Perez, N., Pey, J., Querol, X., Alastuey, A., Lopez, J. M., and Viana, M.: Partitioning of major and trace components in $\mathrm{PM}_{10}-\mathrm{PM}_{2.5^{-}}$ $\mathrm{PM}_{1}$ at an urban site in Southern Europe, Atmos. Environ., 42(8), 1677-1691, 2008.

Powell, K., Taylor, R., Cronin, A., Barrett, M., Pedley, S., Sellwood, J., Trowsdale, S., and Lerner, D.: Microbial contamination of two urban sandstone aquifers in the UK, Water Res., 37(2), 339352, 2003.

Puust, R., Kapelan, Z., Savic, D. A., and Koopel, T.: A review of methods for leakage management in pipe networks, Urban Water J., 7(1), 25-45, 2010.

Querol, X., Alastuey, A., Moreno, T., Viana, M. M., Castillo, S., Pey, J., Rodriguez, S., Artinano, B., Salvador, P., Sanchez, M., Dos Santos, S. G., Garraleta, M. D. H., Fernandez-Patier, R., Moreno-Grau, S., Negral, L., Minguillon, M. C., Monfort, E., Sanz, M. J., Palomo-Marin, R., Pinilla-Gil, E., Cuevas, E., de la Rosa, J., and de la Campa, A. S.: Spatial and temporal variations in airborne particulate matter $\left(\mathrm{PM}_{10}\right.$ and $\left.\mathrm{PM}_{2.5}\right)$ across Spain 1999-2005, Atmos. Environ., 42(17), 3964-3979, 2008.

Rivers, C. N., Barrett, M. H., Hiscock, K. M., Dennis, P. F., Feast, N. S., and Lerner, D. N.: Use of nitrogen isotopes to identify nitrogen contamination of the Sherwood sandstone aquifer beneath the city of Nottingham, UK, Hydrogeol. J., 4(1), 90-102, 1996.

Rueedi, J., Cronin, A. A., Taylor, R. G., and Morris, B. L.: Tracing sources of carbon in urban groundwater using delta C-13(TDIC) ratios, Environ. Geol., 52(3), 541-557, 2007.

Sánchez-Vila, X., Dentz, M., and Donado, L. D.: Transportcontrolled reaction rates under local non-equilibrium conditions, Geophys. Res. Lett., 34(10), L10404, doi:10.1029/2007GL029410, 2007.

Schemel, L. E., Cox, M. H., Runkel, R. L., and Kimball, B. A.: Multiple injected and natural conservative tracers quantify mixing in a stream confluence affected by acid mine drainage near Silverton, Colorado, Hydrol. Process., 20(13), 2727-2743, 2006.

Taylor, R. G., Cronin, A. A., Lerner, D. N., Tellam, J. H., Bottrell, S. H., Rueedi, J., and Barrett, M. H.: Hydrochemical evidence of the depth of penetration of anthropogenic recharge in sandstone aquifers underlying two mature cities in the UK, Appl. Geochem., 21(9), 1570-1592, 2006.

Thornton, J., Sturm, R., and Kunkel, G.: Water Loss Control, McGraw-Hill Professional, Second Edition, 632 pp., 2008.

Trauth, R. and Xanthopoulos, C.: Non-point pollution of groundwater in urban areas, Water Res., 31(11), 2711-2718, 1997.

Trowsdale, S. A. and Lerner, D. N.: A modelling approach to determine the origin of urban ground water, J. Contam. Hydrol., 91(1-2), 171-183, 2007.
Trowsdale, S. A. and Lerner, D.: Implications of flow patterns in the sandstone aquifer Veneta the mature conurbation of Nottingham (UK) for source protection, Q. J. Eng. Geol. Hydroge., 36(3), 197-206, 2003.

Valdés, J. and Castelló, J.: The Management of Distribution Networks by Sectors and the Barcelona Experience, http://paginas.fe.up.pt/_mjneves/publicacoesfiles/data/es/ ponencias/porautor/pdf/10043.pdf, last access: 20 January 2010, in: IWA, ed., II International Conference on efficient use and Management of water in urban areas, 2003.

Vázquez-Suñé, E., Capino, B., Abarca, E., and Carrera, J.: Estimation of recharge from floods in disconnected stream-aquifer systems, Ground Water, 45(3), 579-589, 2007.

Vázquez-Suñé, E., Castillo, O., Sánchez-Vila, X., Alberich, C., and Carrera, J.: Use of natural and anthropogenic tracers to identify sources of groundwater recharge in urban areas in Barcelona, in: Tracers and modelling in hydrogeology, edited by: Dassargues, A., IAHS Publ. no. 262, 363-369, 2000.

Vázquez-Suñé, E. and Sánchez-Vila, X.: Groundwater modelling in urban areas as a tool for local authority management: Barcelona case study (Spain), in: Impacts of urban growth on surface water and groundwater quality, edited by: Ellis, J. B., IAHS no. 259, 65-72, 1999.

Vázquez-Suñé, E., Sánchez-Vila, X., and Carrera, J.: Introductory review of specific factors influencing urban groundwater, an emerging branch of hydrogeology, with referente to Barcelona, Spain, Hydrogeol. J., 13(3), 522-533, 2005a.

Vázquez-Suñé, E., Sánchez-Vila, X., Carrera, J., and Arandes, R.: When intensive exploitation is a blessing: effects of ceasing intensive exploitation in the city of Barcelona, in: Groundwater intensive use, edited by: Sahuquillo, A., Capilla, J., Martinez Cortina, L., and Sanchez-Vila, X., AIHS Selected Papers, Balkema, 253-260, 2005b.

Verstraeten, I., Fetterman, G., Meyer, M., Bullen, T., and Sebree, S.: Use of tracers and isotopes to evaluate vulnerability of water in domestic wells to septic waste, Ground Water Monit. R., 25(2), 107-117, 2005.

Wakida, F. and Lerner, D. N.: Non-agricultural sources of groundwater nitrate: a review and case study, Water Res., 39(1), 3-16, 2005.

Wakida, F. T., Ponce-Serrano, L. E., Mondragon-Silva, E., GarciaFlores, E., Lerner, D. N., and Rodriguez-Ventura, G.: Impact of a polluted stream on its adjacent aquifer: the case of the Alamar zone, Tijuana, Mexico, in: Bringing groundwater quality research to the watershed scale, edited by: Thomson, N. R., AIHS Publ. no. 297, 141-147, 2005.

Wolf, L., Held, I., Eiswirth, M., and Hotzl, H.: Impact of leaky sewers on groundwater quality, Acta Hydroch. Hydrob., 32(45), 361-373, 2004.

Yang, Y., Lerner, D., Barrett, M., and Tellam, J.: Quantification of groundwater recharge in the city of Nottingham, UK, Environ. Geol., 38(3), 183-198, 1999. 